\begin{tabular}{|c|c|c|}
\hline BENTHAM OPEN & The Open Civil Engineering Journal & $\begin{array}{l}\text { The Open } \\
\text { Cvil tengine. }\end{array}$ \\
\hline CrossMark & Content list available at: www.benthamopen.com/TOCIEJ/ & 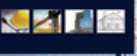 \\
\hline & DOI: $10.2174 / 1874149501711010109$ & \\
\hline
\end{tabular}

RESEARCH ARTICLE

\title{
Electro-Osmosis Chemical Treatment of High-Salinity Soft Marine Soils: Laboratory Tests
}

\author{
Lei Zhang ${ }^{1}$, Li-ping Jing ${ }^{1, *}$, Ning-wei Wang ${ }^{2}$, Chen Fang ${ }^{3}$, Yong-qiang Li $^{1}$ and Zhen-dong Shan ${ }^{1}$ \\ ${ }^{\prime}$ Key Laboratory of Earthquake Engineering and Engineering Vibration, Institute of Engineering Mechanics, China \\ Earthquake Administration, Harbin 150080, China \\ ${ }^{2}$ School of Civil Engineering, Shenyang Jianzhu University, Shenyang 110168, China \\ ${ }^{3}$ Department of Civil Engineering, University of Nebraska-Lincoln, Lincoln, NE 68588, USA
}

Received: June 13, 2016

Revised: October 17, 2016

Accepted: October 31, 2016

\begin{abstract}
The electro-osmosis chemical treatment (ECT) is a useful method for improving soil strength. Some laboratory tests on ECT for strengthening high-salinity soft marine soils were investigated using self-designed laboratory facilities in this research. This study focused on improving the mechanical properties by using ECT method and analyzed the effects of using $\mathrm{CaCl}_{2}$ solution on soil strength owing to the electrolyte is an important factor for improving the bearing capacity of the high-salinity marine soils. Three groups of tests with different time for consolidation were performed to analyze the effective consolidation time on the ECT. In addition, several practical issues, including the current, voltage, energy consumption and the bearing capacity of the treated soils before and after experiments, were considered in the tests. The laboratory tests results demonstrated that the ECT technique is an effective method for improving the high-salinity marine soft soils. Furthermore, the definition of the effective time for consolidation was proposed for the ECT of high-salinity soft marine soils to improve the feasibility and economical efficiency of the ECT. This study provides some references and suggestions for practical application of the ECT technique for marine soft soils.
\end{abstract}

Keywords: High-salinity soft marine soils, Electro-osmosis chemical treatment, Effective time for consolidation, Bearing capacity, Calcium chloride solution.

\section{INTRODUCTION}

Electro-osmotic consolidation (EC) is an attractive technique to improve the strength and durability of soils. In this technique, the flow of pore water occurs from the anode toward the cathode under the electric field in soils [1]. Based on EC technique, the electro-osmosis chemical treatment (ECT) method is developed for improving the bearing strength of the soil. The ECT method is feasible to enhance the physical and mechanical properties of the soil to meet the requirements of consolidation. With the ECT, the positive metal ions at the surface soil are combined with the water molecules to generate some hydrated ions, and the water flows from the anode toward the cathode under the electric current. The process is referenced as the dewatering of soils. The dewatering process results in the increase in the strength of the soils. In addation, the chemical reactions including ion exchange, chemical cementation, and ionic precipitation leads to the consolidation of the soil to increase its strength. These processes are summarized as the strengthening mechanism of ECT method.

Since the introduction of EC into geotechnical engineering by Casagrande [2 - 4], the EC technique has been used for the stabilization of various soils to improve their strength and durability [5 - 14]. A useful analytic model of electroosmosis-enhanced preloading consolidation via vertical drains for clayey soils was developed by Shang [15]. Zhuang analyzed and discussed the interfacial resistance during electro-osmosis consolidation, and investigated on the electrode

* Address correspondence to this author at the Key Laboratory of Earthquake Engineering and Engineering Vibration, Institute of Engineering Mechanics, China Earthquake Administration, Harbin 150080, China; Tel: +86-130-3999-79-363,+86-185-0210-2765; E-mails: ray_iem@163.com, jing_liping@126.com 
materials in the strengthening period [16]. Hu provided a theoretical model for electro-osmotic consolidation using several experimental tests, and also developed a FEM software to describe the process of electro-osmotic consolidation [1]. The field application of EC for soil improvement has been successfully demonstrated for building structures [2 - 5, $17,18]$. However, it is clear to notice the disadvantages of the EC technique, including severe erosion of the electrode and excessive electric use [19 - 22].

Based on previous studies and engineering practices $[5,7,8]$, adding a salt solution, i.e., ECT, could enhance the electrical conductivity of the soil [23], increase the speed of dewatering, and promote the aggregation of soil particles caused by ion exchange [24 - 26]. Many researchers have been performed on the ECT. Gray [27] used the solution of aluminum chloride in the experiment to analyse the consolidation process of the ECT. Ozkan [28] investigated the stabilization method for a kaolinite bed by injecting aluminium and phosphate ions, and the method caused the increase in the shear strength of 500-600\% and in the liquid limit of 30\%. Asavadorndeja and Glawe [29] developed an innovative method of electro-osmosis consolidation coupled with a depolarization technique and also demonstrated its effectiveness to improve the quality of the electro-osmosis stabilization in soft soils. Chien [24] investigated ground improvements using ECT and discussed soil improvements using electro-osmosis with salt solution injection. Ou [25, 30] performed a series of experiments on precipitated clay in Taipei using self-designed apparatus to analyze the effects of different types and concentrations of salt solutions on strengthening soft clay. Chang [31] carried out tests to determine the relationships between different factors and the improvement of soil strength. Furthermore, the use of a salt solution may result in chemical precipitation under certain conditions, resulting in the generation of cementing substances [31, 32]. After the electrodes are charged, ionic precipitation occurs to mobilize the soil particles and increases the strength of the clay soils [14].

Many researchers have reported the effectiveness of ECT for clayey and silty soils, but few studies have discussed the effective time for consolidation of ECT on untreated high-salinity soft marine soils. Based on this problem, this study was conducted to investigate the effective charging time when using ECT for high-salinity soft marine soils. Furthermore, the effective charging time was obtained by analysis on several parameters, including the current, average resistance, energy consumption and bearing capacity of soils before and after testing. When the testing was finished, the strengths of the treated soils were measured using a pocket penetrometer in the laboratory experiment. Finally, the feasibility and effectiveness of ECT of high-salinity soft marine soils were further demonstrated in this research. The results of this research also provide some references for the application of ECT for marine clayey soils in future engineering projects.

\section{LABORATORY EXPERIMENTAL}

\subsection{Fundamentals of Electro-Osmosis Chemical Treatment}

The consolidation process of the ECT consists of electro-osmotic grouting, chemical cementation, electrolysis, and ion exchange [14]. Electro-osmosis is an electrokinetic phenomenon in the soils caused by coupling between electrical field and liquid [33]. In the ECT, an electric current is applied through electrodes to pass through the soil, and the liquid flows from the anode toward the cathode under the electrical current. A tension that is defined as a negative pore water pressure develops in the pore water during the electro-osmosis consolidation. With the tension, the pore water of the soil moves from the anode to the cathode. According to the theory of the effective stress [34], the effective stress in the soil is positive owing to the constant total stress and the negative pore water stress. The effective stress in the soil is in equilibrium with the tension, and therefore the strength of the soil is improved by the dewatering process [9 - 14].

Cementation is caused by the electro-osmosis erosion of steel pole and the chemical reaction of calcium ion. The oxidizing reaction occurs in the anode, and $1 \mathrm{~g}$ iron is dissolved when $1 \mathrm{~A} \cdot \mathrm{h}$ is charged based on the theory of ECT. Every $1 \mathrm{~cm}^{3}$ iron (approximately $7.85 \mathrm{~g}$ ) is dissolved to generate $300 \mathrm{~cm}^{3} \mathrm{Fe}(\mathrm{OH})_{3} \cdot \mathrm{nH} 2 \mathrm{O}$. The $\mathrm{Fe}(\mathrm{OH})_{3} \cdot \mathrm{nH} 2 \mathrm{O} \mathrm{moves}$ to the cathode under the electric field. Some dry colloids are generated owing to the dehydration in the process of consolidation. These colloids have the cementation effect on the soils. In addition, the calcium hydroxide is generated by the chemical reaction between the calcium ions and the hydroxide ions obtained from the decomposition of the water. Some calcium carbonates are yielded due to the chemical reaction between calcium hydroxide and carbon dioxide. More calcium carbonates are formed in the chemical reaction between the existed calcium hydroxide and the added calcium chloride. Consequently, the calcium carbonates fill the pores of the soil and also enhance the adhesive forces among the soil grains. As a results, the chemical reactions during the ETC result in the consolidation of the soil to increase its bearing capacity. The chemical reactions are summarized as follows: 
Anode:

$$
\begin{gathered}
\mathrm{Fe}+\mathrm{O}_{2} \rightarrow \mathrm{Fe}_{2} \mathrm{O}_{3} \\
\mathrm{Fe}_{2} \mathrm{O}_{3}+\mathrm{H}^{+} \rightarrow \mathrm{Fe}^{3+} \\
\mathrm{Fe}^{3+}+\mathrm{OH} \rightarrow \mathrm{Fe}(\mathrm{OH})_{3} \downarrow
\end{gathered}
$$

Cathode:

$$
\begin{gathered}
2 \mathrm{H}_{2} \mathrm{O}+2 e^{-} \rightarrow 2 \mathrm{OH}+\mathrm{H}_{2} \uparrow \\
\mathrm{N}^{2+}+2 \mathrm{OH} \rightarrow \mathrm{N}(\mathrm{OH})_{2} \\
\mathrm{~N}(\mathrm{OH})_{2}+\mathrm{CO}_{2} \rightarrow \mathrm{NCO}_{3} \downarrow+\mathrm{H}_{2} \mathrm{O}
\end{gathered}
$$

Where, $\mathrm{N}$ represents the metal positive ion including $\mathrm{Ca}^{2+}, \mathrm{Mg}^{2+}$.

The electrolysis yields some gases, including the oxygen in the anode and the hydrogen in the cathode. The chemical reactions regarding the electrolysis are shown as followed:

Anode:

$$
\mathrm{H}_{2} \mathrm{O} \rightarrow \mathrm{O}_{2} \uparrow+H^{+}+e^{-}
$$

Cathode:

$$
\mathrm{H}_{2} \mathrm{O}+e^{-} \rightarrow \mathrm{OH}+\mathrm{H}_{2} \uparrow
$$

Ionic exchange happens substituting the high-valence ions in the salt solution $\left(\mathrm{Ca}^{2+}, \mathrm{Al}^{3+}\right)$ with the low-valence ions in the high-salinity soft marine soils $\left(\mathrm{K}^{+}, \mathrm{Na}^{+}\right)$. The radius of the hydrated ion is reduced owing to the ionic exchange, and hence the thickness of the electrical double layer decreases the cohesive forces among the soil grains. The exchanging ability of positive ions is described as the ability of positive ions to exchange other positive ions from the colloid. The order of the exchanging ability of positive ions can be presented as, $\mathrm{Fe}^{3+}>\mathrm{Al}^{3+}>\mathrm{H}^{+}>\mathrm{Ca}^{2+}>\mathrm{Mg}^{2+}>\mathrm{K}^{+}>\mathrm{Li}^{+}>\mathrm{Na}^{+}$ [35].

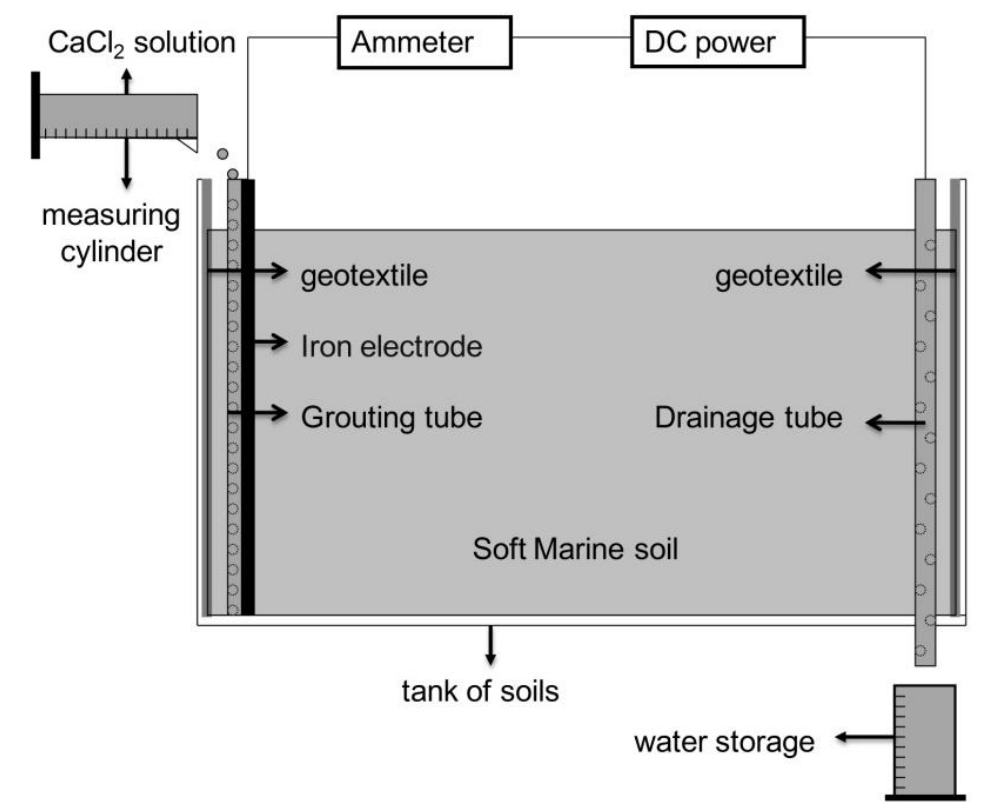

Fig. (1). Schematic configuration of the electro-osmosis chemical treatment.

\subsection{Experimental Facilities}

The paper investigated the characteristics of each parameter in the testing of ECT for high-salinity soft marine soils using self-designed laboratory facilities. According to the theory of the ECT, the experimental facilities include as 
follows: (1) Test tanks of soils. The test tank with dimensions of $300 \mathrm{~mm} \times 200 \mathrm{~mm} \times 250 \mathrm{~mm}$ made of the engineered plastics was used during the process of ECT. (2) Electrodes and a grouting tube. Steel pipes with a diameter of $8 \mathrm{~mm}$ and a length of $300 \mathrm{~mm}$ were inserted into the soil to a depth of $200 \mathrm{~mm}$ acted as the cathodes. Steel bars with a diameter of $5 \mathrm{~mm}$ and same length were acted as anodes. The PVC pipes with a diameter of $15 \mathrm{~mm}$ were bundled with the anodes to inject the salt solution. For the traditional method, the salt solution was injected into the steel pipe, and the steel pipe ruptured quickly when charged. The rupture of the pipe was always initiated at the soil-water-air interface, where the water vapor exchange and rapid chemical reactions resulted in high rates of anode erosion. Using a PVC pipe to inject the salt solution was a useful approach for reducing anode erosion. (3) A direct current power with a current of $0 \sim 30 \mathrm{~A}$ and a voltage of $0 \sim 100 \mathrm{~V}$. (4) Some auxiliary apparatuses. The auxiliary apparatuses that were prepared for the test including multimeters, soil conductivity meters, pocket penetrometers, thermometers and so forth, were prepared for the test. The testing was designed to investigate the ECT for high-salinity soft marine soils, and some general considerations included the prevention on the entire system from short circuiting and ensuring that eroded electrodes could easily be replaced. The schematic configuration of the ECT is shown in Fig. (1).

\subsection{Soil Specimens}

The experiment was carried out on soils collected from a silty clay deposit in the coastal industrial base of Yingkou city. The soils were obtained at the site at a depth of $12 \mathrm{~m}$ and then transported to the laboratory. The samples of highsalinity soft marine soils with grey-black color had low bearing capacities. The physical and mechanical properties of these untreated soils are listed in Table 1. In the three groups of testing, the basic parameters of the soils include the initial water content of the soil, the electrode spacing, the degree of saturation, the void ratio and so forth are identical in order to analyze the effective charging time.

Table 1. Physical and mechanical properties of high-salinity soft marine soils.

\begin{tabular}{|c|c|c|c|c|c|c|c|c|c|}
\hline $\boldsymbol{w} / \boldsymbol{\%}$ & $\boldsymbol{\rho} / \mathbf{g} / \mathbf{c m}^{\mathbf{3}}$ & $\boldsymbol{S}_{\boldsymbol{r}} / \boldsymbol{\%}$ & $\boldsymbol{e}$ & $\boldsymbol{I}_{\boldsymbol{P}}$ & $\boldsymbol{I}_{\boldsymbol{L}}$ & $\boldsymbol{E}_{\boldsymbol{S}} / \mathbf{M P a}$ & $\boldsymbol{C}_{q} / \mathbf{k P a}$ & $\boldsymbol{\varphi}_{q} /{ }^{\circ}$ & $\boldsymbol{f}_{a} / \mathbf{k P a}$ \\
\hline 45.72 & 1.76 & 98.91 & 1.257 & 15.9 & 1.64 & 2.08 & 5.7 & 2.6 & 40 \\
\hline
\end{tabular}

Note: $w$ represents the water content of the soil; $\rho$ is the density of the soil; $S_{r}$ is the degree of saturation of the soil; $e$ is the initial void ratio of the soil; $I_{P}$ is the plasticity index of the soil; $I_{L}$ is the compressibility coefficient of the soil; $E_{s}$ is the compressive modulus of the soil; $C_{q}$ is the cohesive force of the soil; $\varphi_{q}$ is the angle of friction of the soil; and $f_{a}$ is the characteristic value of bearing capacity of the soil.

The purpose of the study is to investigate the effective charging time of the ECT. The test parameters of the experiment are shown in Table $2 . \mathrm{CaCl}_{2}$ solution was selected as the electrolyte for the experiment and the concentration of the salt solution injected in the anode was $2 \mathrm{~mol} / \mathrm{L}$. The total amount of $\mathrm{CaCl}_{2}$ solution and the moment to add the salt solution were identical. The moments to add the solution were charging $2 \mathrm{~h}, 5 \mathrm{~h}, 8 \mathrm{~h}$, and $15 \mathrm{~h}$. The amount of $20 \mathrm{ml}$ solution was injected at each moment. The soil samples were covered with a plastic membrane to prevent evaporation. Then, the electrodes were passed through the plastic membrane and inserted into the soil. The power supply was connected to these electrodes, and the control parameters of voltage were set before testing. Changes in the electrical potential and current were recorded to calculate the average resistance.

Table 2. Test parameters of the experiment.

\begin{tabular}{|l|c|c|c|c|c|c|}
\hline & Voltage (V) & Electrode spacing (cm) & $\begin{array}{c}\text { Potential gradient } \\
(\mathbf{V} / \mathbf{c m})\end{array}$ & $\begin{array}{c}\text { Concentration of } \mathbf{C a C l}_{\mathbf{2}} \\
(\mathbf{m o l} / \mathbf{L})\end{array}$ & $\begin{array}{c}\text { Total amount of solution } \\
(\mathbf{m L})\end{array}$ & Charging time (h) \\
\hline T 1 & 20 & 20 & 1 & 2 & 80 & 20 \\
\hline T 2 & 20 & 20 & 1 & 2 & 80 & 30 \\
\hline T 3 & 20 & 20 & 1 & 2 & 80 & 40 \\
\hline
\end{tabular}

\section{RESULTS AND DISCUSSIONS}

\subsection{Experimental Results}

A series of chemical reactions were performed on the consolidation of the high-salinity marine soft soil under the electric field. Air bubbles appeared in the cathode and some tawny colored water spilled out of the soil. After charging for 30 minutes, some black-green substances were found in the electrodes. During testing, the temperature of the soil increased because heat was released in the oxidation reactions. The phenomena demonstrated that the exothermic chemical reactions also occurred during the process of electro-osmosis. Furthermore, some gases with pungent smells were produced and vented from the soils. The gases were regarded as the chlorine gas produced from the oxidation reaction and the electrolysis. Based on the previous studies, the gases were composed of $\mathrm{H}_{2} \mathrm{~S}_{\text {and }} \mathrm{SO}_{2}[9,13,14,36]$. 
In the experiment, some white substances were also produced at the surface of the soils. These substances were formed in the chemical reactions between the injected salt solution and the saline ingredients of the soil during the testing. After charging $12 \mathrm{~h}$, the cracks were found near the anode. With the increase in the charging time, the cracks increased and developed to the cathode. The distributions of the cracks were related to wet-dry change of the soil and the distribution of the electric potential in the soil. The development of the cracks in the soil was shown in Figs. (2-5).

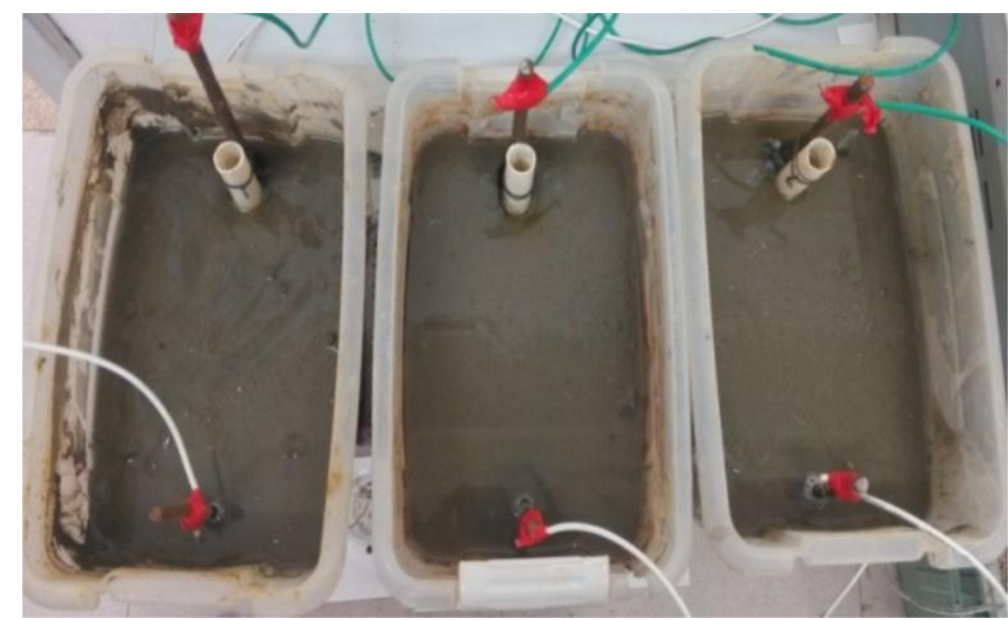

Fig. (2). Charging 3h, the hydrated soil in cathode.

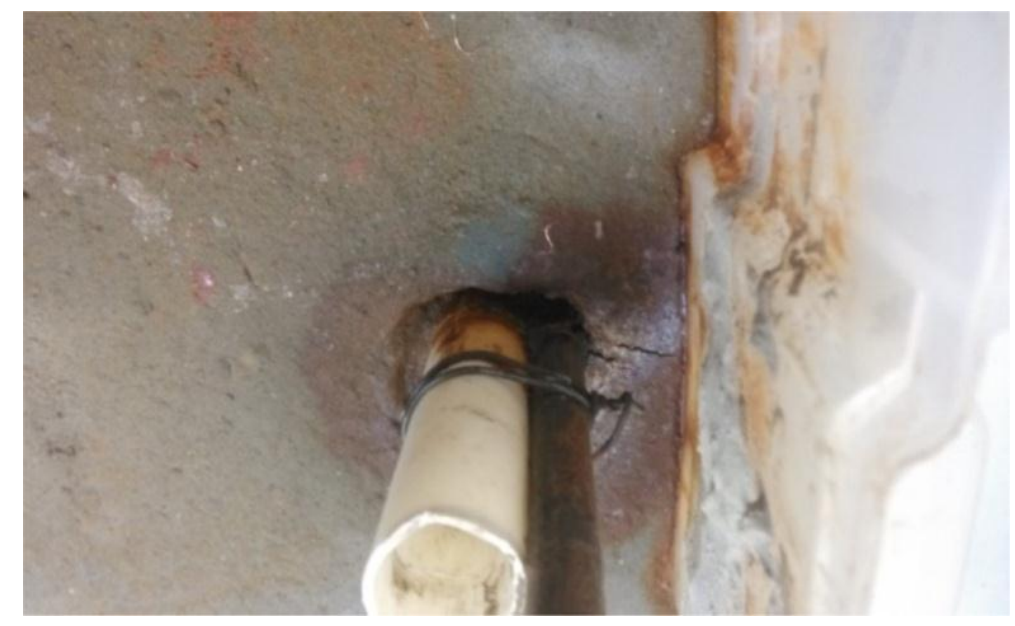

Fig. (3). Charging 12h, cracks generated in anode.

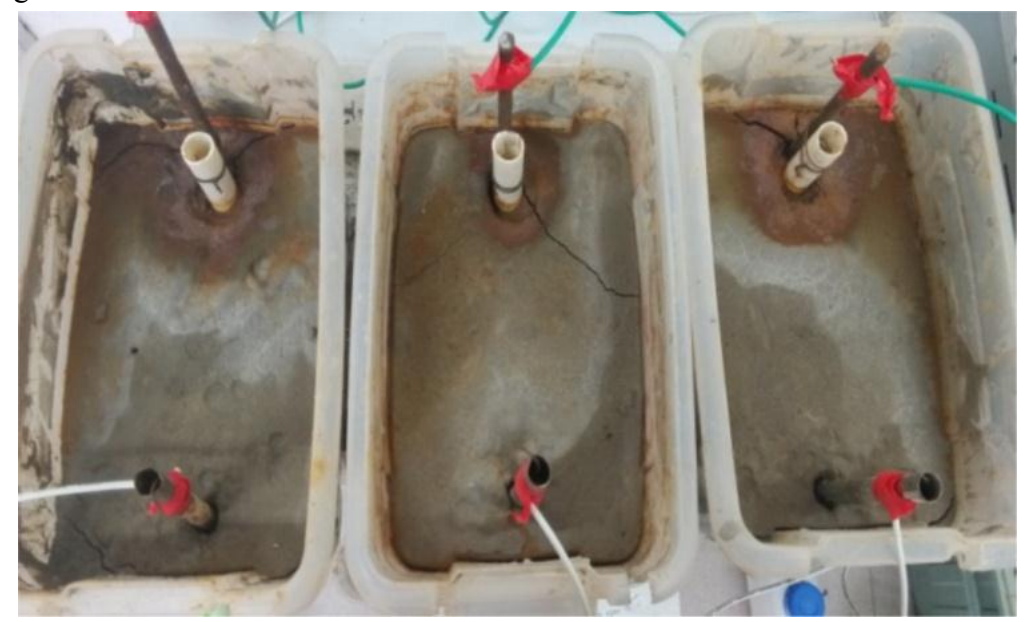

Fig. (4). Charging 20h, appearance of white substances. 


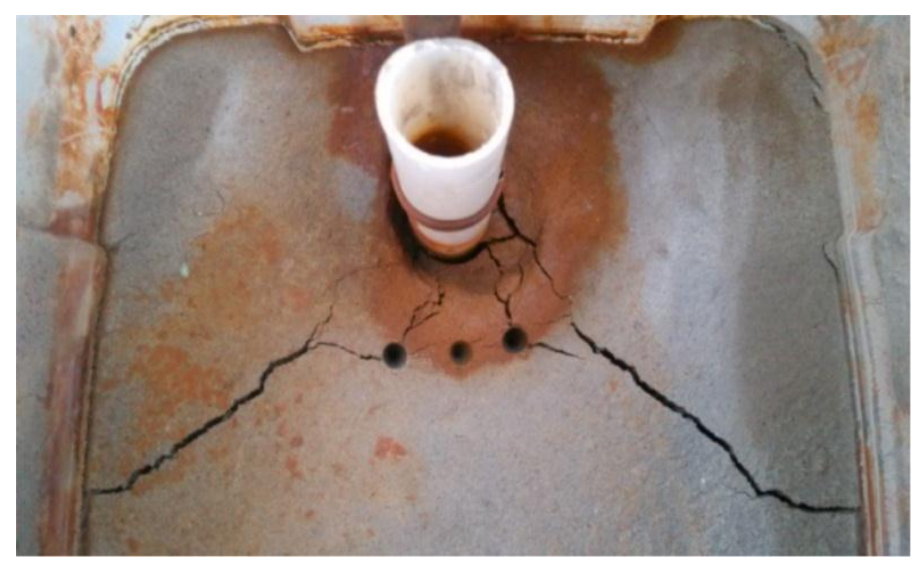

Fig. (5). Charging finished.

Cross-sections of the tested soils containing organic matters are shown in Fig. (6). It was clear that the organic matters were formed during the tests and that the generated organic matters potentially contained iron oxides (i.e., Iron (II) oxide, Iron (III) oxide-hydroxide, and Iron (II) hydroxide) [9, 13, 14, 21, 22, 36]. However, the proportion of these organic matters was not determined by testing. Accordingly, the results of the current study may require adjustment based on future research. During the testing, the temperature of the soil was also measured using a thermometer. The maximum temperature received was about $260^{\circ} \mathrm{C}$. The increase of the temperature of the soil was owing to the heat released in the chemical reactions. These phenomena demonstrated that the chemical reactions occurred in the steel electrodes when the electrodes were charged.
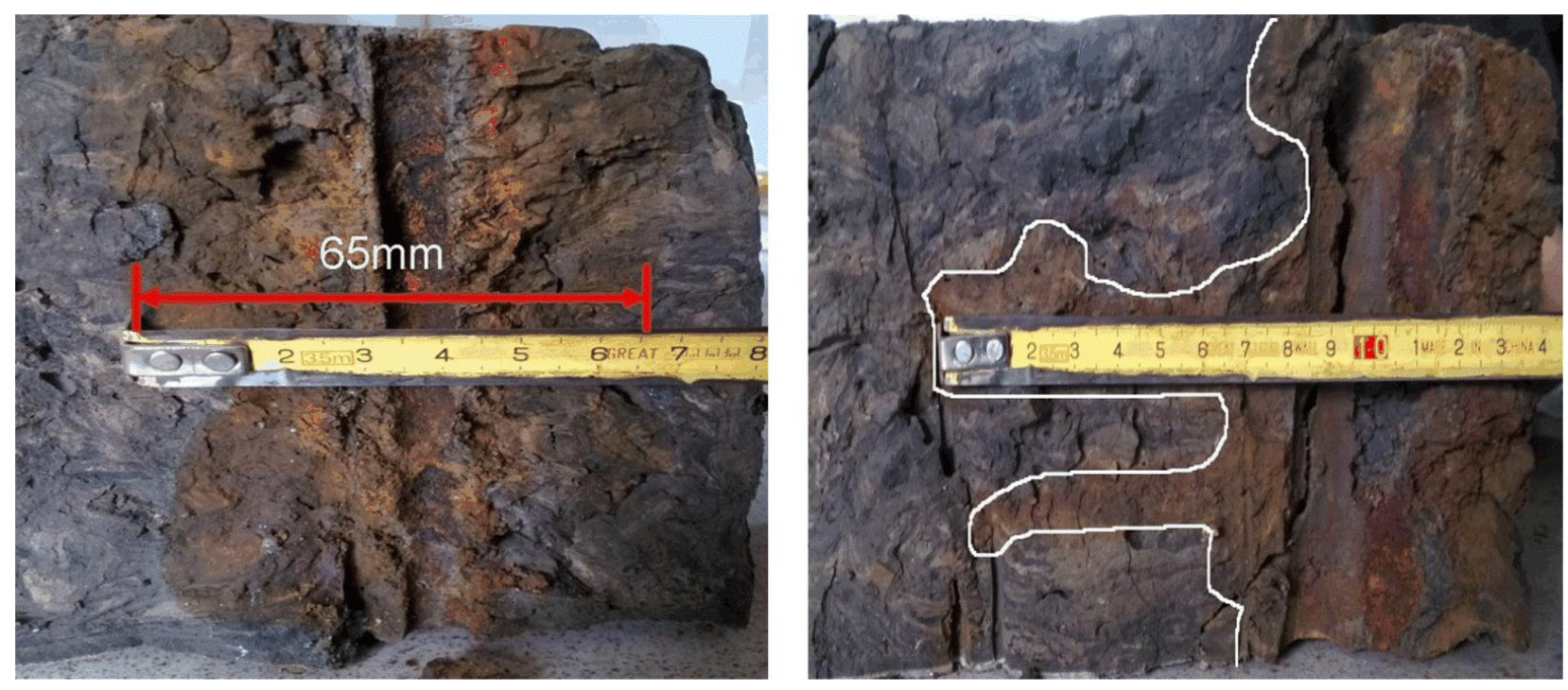

Fig. (6). Organic matters existed in the soft marine soils.

\subsection{Current}

Fig. (7) shows the changes of current with time in the ECT. It is clear that the changes of the current in these tests were almost identical owing to the same parameters in these groups of testing. The maximum currents in these three groups of testing were appeared at 2 hours, and the maximum value of the current was shown at the beginning of charging based on the principle of ECT. With the increase in the charging time, the currents reduced. The appearance of the maximum current at 2 hours is due to the addition of the $\mathrm{CaCl}_{2}$ solution. The injection of $\mathrm{Ca}^{2+}$ improved the ionic movement in the soils and increased the moving speed and the exchanging rate of the ions. At the moments of $5 \mathrm{~h}, 8 \mathrm{~h}$, and $15 \mathrm{~h}$, the $\mathrm{CaCl}_{2}$ solution was added to the testing, and the peaks of the current appeared in the curves. The appearance of these peaks demonstrates the effect of $\mathrm{Ca}^{2+}$ on the current of the soil during the consolidation process. 


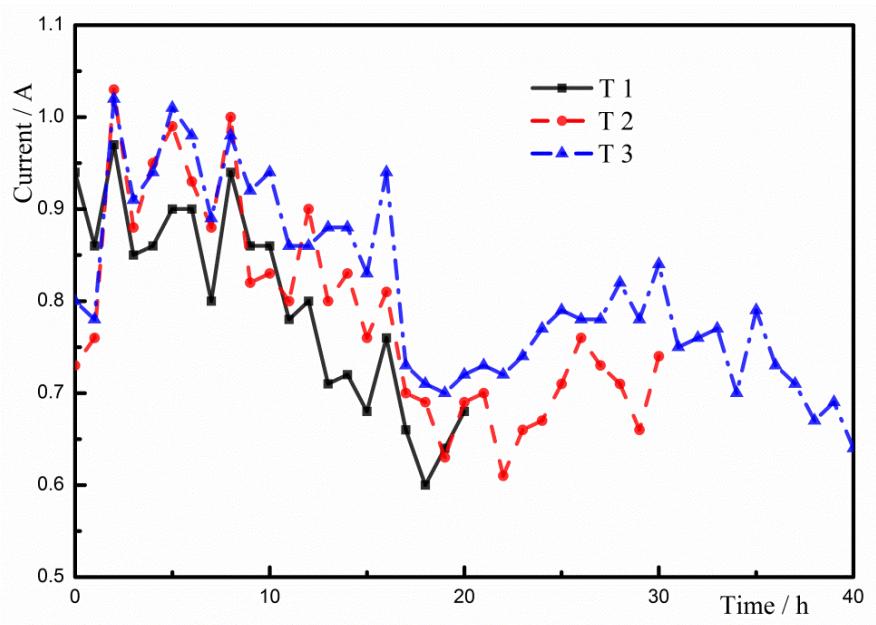

Fig. (7). Changes in current with time.

\subsection{Average Resistance}

The average resistance of the soil is defined as the ratio of the voltage and the current during the test. The changes of average resistances in these tests were received based on the Ohm's law, shown in Fig. (8). According to Fig. (7) and Fig. (8), the changes of average resistance were different from the changes of current. It was concluded that the conductivity of the soil was improved when the $\mathrm{CaCl}_{2}$ solution was injected in the test. The increased conductivity of the soil resulted in the increase in the current during the testing. The analysis demonstrated that the injection of the salt solution had an essential influence on the current during the testing, and the effect of injecting the salt solution was previously proven by Lefebvre [23]. The minimum average resistances in these three groups of testing occurred at 2 hours. The currents of the soils reached the maximum values owing to adding $\mathrm{CaCl}_{2}$ solution. Based on the Ohm's law, the average resistance of the soil should be minimum at 2 hours. Several factors, including the water content of the soil, the degree of saturation, and the void ratio, had an effect on the resistance of the soil. With the development of testing, the water content of the soil reduced due to the ECT. The decrease in the water content enhanced the resistance of the soil. During the process of ECT, the electrolysis on the iron anode, the ion movement, and the ionic precipitation would be the influencing factors on the resistances of the soils. Therefore, the change of resistance is related to the change of current.

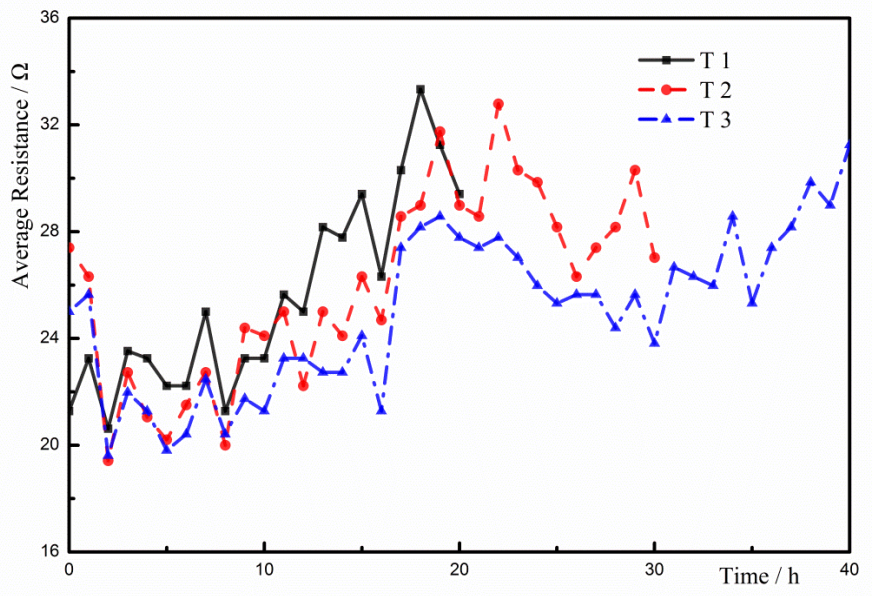

Fig. (8). Changes in average resistance with time.

\subsection{Energy Consumption}

The voltage was set as $20 \mathrm{~V}$. According to the voltages and currents in these groups of testing, the energy consumption of ECT was formulated as Eq. (1). 


$$
C_{t_{2}}=C_{t_{1}}+\int_{t_{1}}^{t_{2}} U_{t} I_{t} d t
$$

In the equation, $U_{t}$ and $I_{t}$ represent the effective voltage and current at a certain time $t$, respectively. $C_{t l}$ and $C_{t 2}$ represent the energy consumption at the moment of $t_{l}$ and $t_{2}$, respectively. $C_{t l}$ is the initial value of the energy consumption which is equal to zero without charging. According to Eq. (1), the energy consumption is related to the current with the same voltage and the charging time. The energy consumption is proportional to the current at a certain time. Fig. (9) showed the changes of the energy consumption with the time in these tests. It is clear that the energy consumption value of $\mathrm{T} 1$ was $0.31 \mathrm{~kW} \cdot \mathrm{h}$, the energy consumption value of $\mathrm{T} 2$ was $0.47 \mathrm{~kW} \cdot \mathrm{h}$, and the energy consumption value of T3 was $0.65 \mathrm{~kW} \cdot \mathrm{h}$. The energy consumption of T3 was larger than other two tests. Based on the changes of the energy consumption, the energy consumption increased with the increase in the charging time. However, the long charging time could increase the cost and reduce the economical efficiency of ECT. The increase in the cost imposed restrictions on the application of the method to the engineering projects.

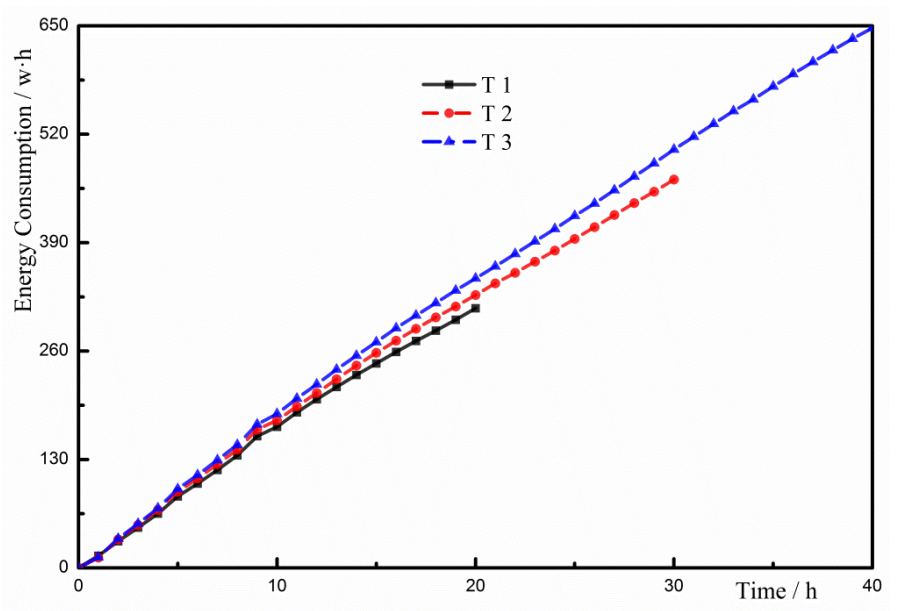

Fig. (9). Changes in energy consumption with time.

\subsection{Bearing Capacity of Soils}

After the experiment had finished, the soils were sealed to place $1 \mathrm{~d}, 2 \mathrm{~d}, 4 \mathrm{~d}, 7 \mathrm{~d}, 11 \mathrm{~d}$, and $14 \mathrm{~d}$. And the bearing capacity of the soil was measured using a pocket penetrometer. The strengthened soils were divided into three parts including anode zone, middle zone, and cathode zone to measure the bearing capacity [9 - 14]. shown in Fig. (10). Based on the distributions of electrodes in the experiment, the zone near the anode was defined as the anode zone; the zone close to the cathode was defined as the cathode zone; the zone located between the anode zone and the cathode zone was defined as the center zone. The divided zones of the soil were shown in Fig. (10). The bearing capacities of the soils in T1, T2, and T3 were shown in Figs. (11-13), respectively.

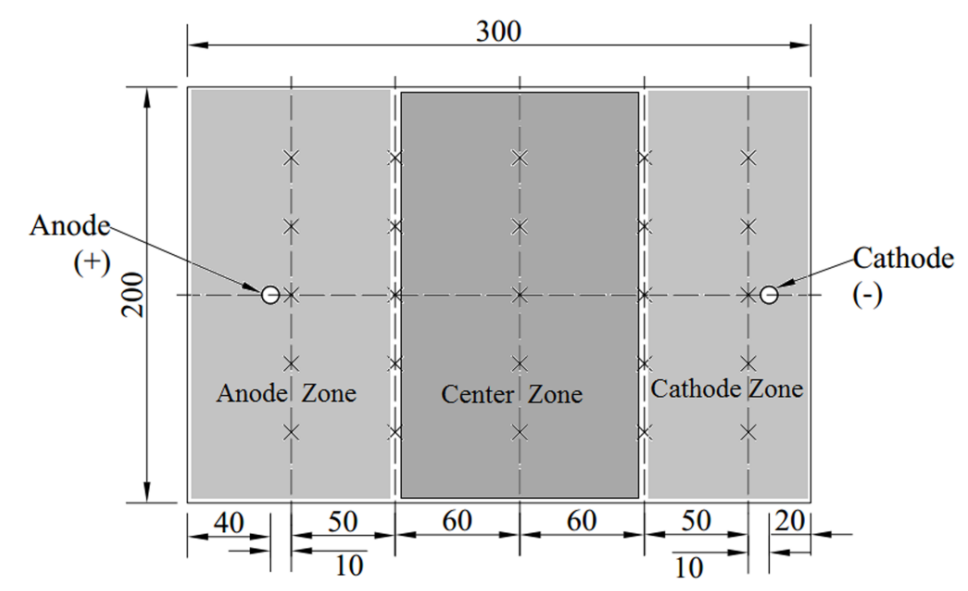

Fig. (10). Measuring points of bearing capacity and the divided zones of the soil. 


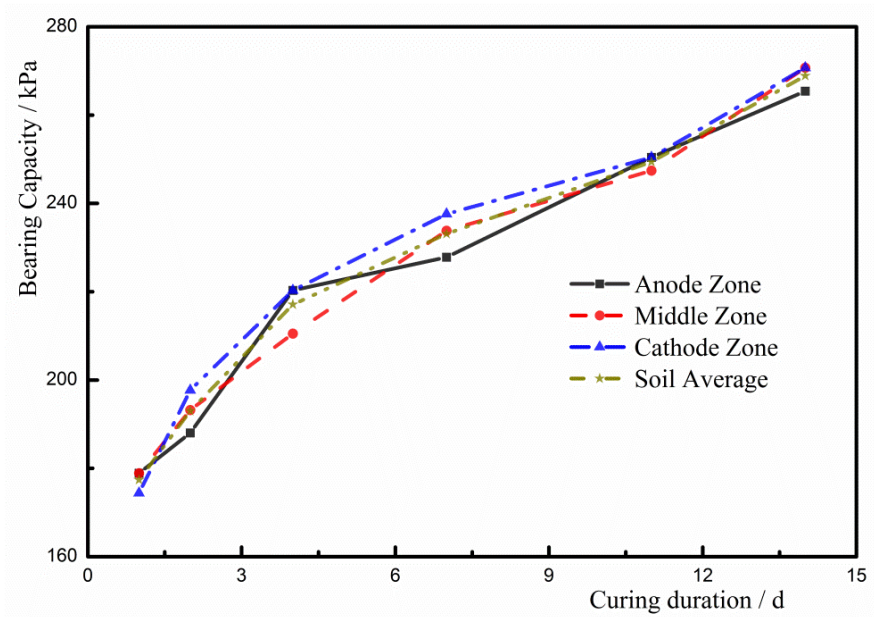

Fig. (11). Bearing capacity of soil in $\mathrm{T} 1$.

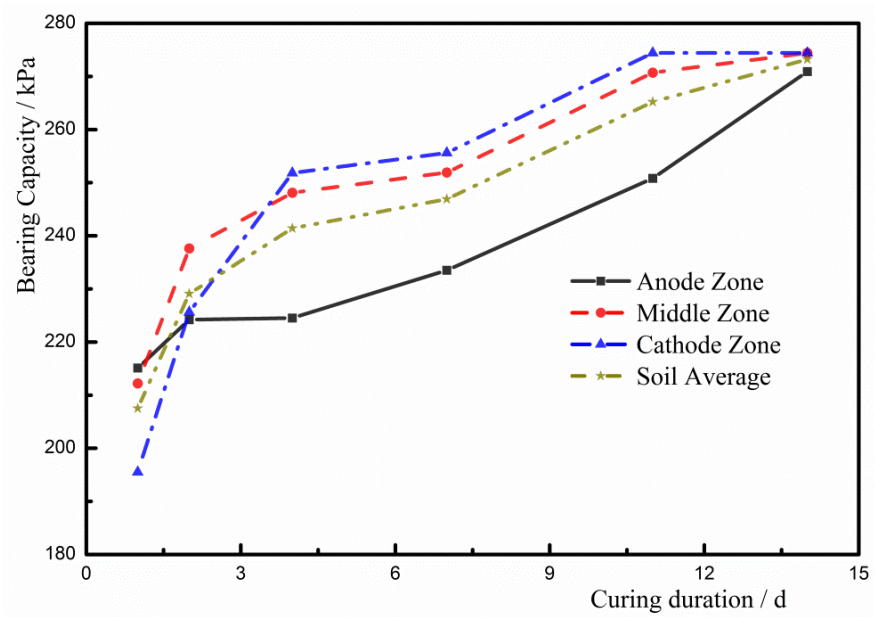

Fig. (12). Bearing capacity of soil in $\mathrm{T} 2$.

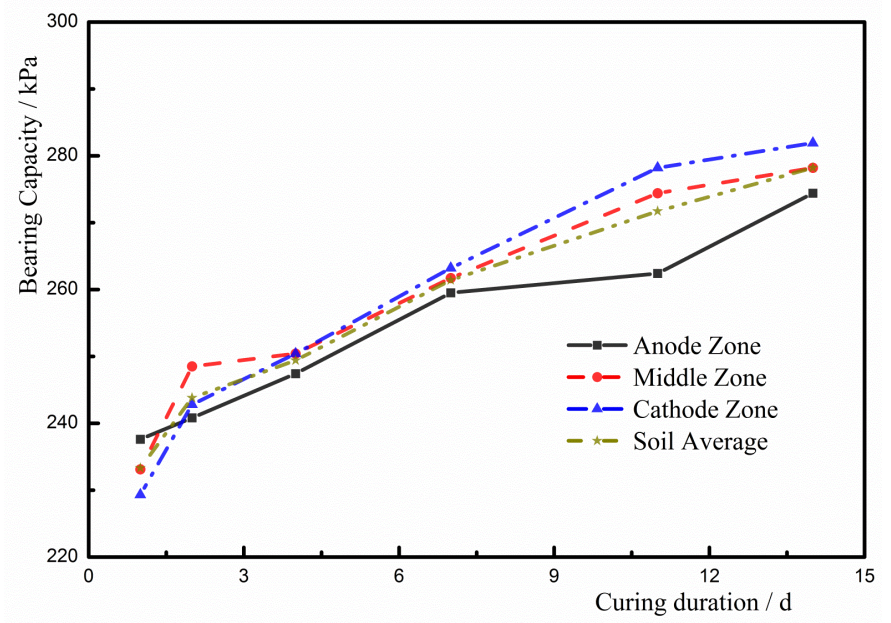

Fig. (13). Bearing capacity of soil in T3.

1. The maximum bearing capacity was determined in the anode zone at the beginning of charging, and the minimum bearing capacity was found in the cathode zone. At first, the free water and the weakly bound water moved to the cathode due to EC. The EC had a dominating effect on the dewatering process. The water content in the cathode zone was larger than other zones. The water content of the soil is the primary factor of determining the bearing capacity of the soil, and hence the bearing capacity in the anode zone is larger than other zones at the beginning of the test. Furthermore, the colloids of the ferric hydroxide in the electrodes have a 
cementing effect on the soils. But less colloid was formed at the beginning of testing, and the soils in the anode zone were influenced by the colloids of the ferric hydroxide. As a result, the bearing capacity of the soils in the anode zone was larger than other zones at the beginning of the test.

2. After charging had finished, the soils were placed for 2 days, and the bearing capacities of the soils in the cathode zone and the middle zone were larger than that in the anode zone. During the process of ECT, ionic exchange was completed in a short duration. EC and the electrolysis were terminated when charging was stopped. However, the ion precipitation $[9,13,14,21-26,30-32,36]$ has an increasing effect on the bearing capacity of the soil. The primary zone where the ion precipitation occurs is the cathode zone, and hence the bearing capacity of the soil in the cathode zone was larger than other two zones.

3. Owing to the ECT method, the average bearing capacity of the high-salinity soft marine soils was improved. After the soils were placed for 17 days, the bearing capacity of the soil was approximately $280 \mathrm{kPa}$, which was improved seven times more than the initial bearing capacity of the soil. And the bearing capacities of the soil in these three zones were distributed more evenly using the ECT method.

4. After charging had finished, the bearing capacity of the high-salinity soft marine soils increased with time. The increase in the bearing capacity with the time demonstrates that the ion precipitation has a dominating influence on the improvement of the bearing capacity of the soil. With the development of the ion precipitation, the bearing capacity of the soil increased.

\section{CONCLUSION}

1. From the experimental testing, the currents of each group reached the maximum values after charging $2 \mathrm{~h}$ and then reduced. Furthermore, the minimum average resistance of the soil was determined after changing $2 \mathrm{~h}$, and then the average resistance of the soil increased. The maximum current in the soil was found after charging $2 \mathrm{~h}$, and then the current reduced.

2. The increase in charging time increased the energy consumption. In the test, the energy consumption in T1 was less than other two tests, and the energy consumption in T3 was larger than that in T1 and T2. However, the ultimate bearing bearings of three groups of testing were almost identical.

3. The ECT method has a strengthening influence on the improvement of the bearing capacity of the high-salinity soft marine soils. The bearing capacity of the soil using the ECT was improved about seven times more than other methods, and the bearing capacity increased with the increase in the curing time.

4. The water content and colloid of the soil had an essential influence on improving bearing capacity of the soil in the anode zone. After charging had finished, the ion precipitation enhanced the bearing capacity of the soil in the cathode zone which was larger than the anode zone.

5. After the testing had been finished, the colloids in the soil were measured to analyze the stability of the soil. The analysis results showed that the stability of the soil was affected by the charging time, and the increase in the charging time improved the stability of the soil.

\section{CONFLICT OF INTEREST}

The authors confirm that this article content has no conflict of interest.

\section{ACKNOWLEDGEMENTS}

This project was supported by the National Natural Science Foundation of China (Grant NOs.51438004 and 51408566) and Scientific Research Fund of Institute of Engineering Mechanics, China Earthquake Administration (Grant Nos. 2013B04 and 2014B03).

\section{REFERENCES}

[1] L. Hu, W. Wu, and H. Wu, "Numerical model of electro-osmotic consolidation in clay", Geotechnique, vol. 62, pp. 537-541, 2012. [http://dx.doi.org/10.1680/geot.11.T.008]

[2] L. Casagrand, "Stabilization of soils by means of electro-osmotic state-of-art", Journal of the Boston Society of Civil Engineers, vol. 69, pp. 255-302, 1983.

[3] L. Casagrand, "Electro-osmosis in soils", Geotechnique, vol. 1, pp. 159-177, 1949.

[http://dx.doi.org/10.1680/geot.1949.1.3.159] 
[4] L. Casagrand, "Electro-osmotic stabilization of soils", Journal of the Boston Society of Civil Engineers, vol. 39, pp. 51-83, 1952.

[5] L. Bjerrum, J. Moum, and O. Eide, "Application of electroosmosis to a foundation problem in a Norwegian quick clay", Geotechnique, vol. 17, pp. 214-235, 1967. [http://dx.doi.org/10.1680/geot.1967.17.3.214]

[6] S. Micic, J.Q. Shang, and K.Y. Lo, "Electrokinetic strengthening of marine clay adjacent to offshore foundations", In: Proceedings of the 11 ${ }^{\text {th }}$ International Offshore and Polar Engineering Conference, 2001, pp. 694-701.

[7] K. Lo, K. Ho, and I. Inculet, "Field test of electroosmotic strengthening of soft sensitive clay", Canadian Geotechnical Journal, vol. 28, pp. 74-83, 1991.

[http://dx.doi.org/10.1139/t91-008]

[8] K. Lo, I. Inculet, and K. Ho, "The effects of electroosmotic field treatment on the soil properties of a soft sensitive clay", Canadian Geotechnical Journal, vol. 28, pp. 763-770, 1991. [http://dx.doi.org/10.1139/t91-093]

[9] L. Zhang, N. Wang, L. Jing, C. Fang, and R. Dong, "Electro-osmosis chemical grouting of mucky clayey soil", Electronic Journal of Geotechnical Engineering, vol. 21, pp. 2061-2070, 2016.

[10] N. Wang, J. Jiao, Y. Xiu, and L. Zhang, "Effect of elec-trode spacing on standard electro-osmotic dewatering", Chinese Journal of Geotechnical Engineering, vol. 34, pp. 177-181, 2012.

[11] N. Wang, L. Zhang, Y. Xiu, and J. Jiao, "Indoor standard electro-osmosis drainage experiment of unsaturated clayey soil", In: The 21 ${ }^{\text {st }}$ National Conference on Structural Engineering, 2012, pp. 460-464.

[12] N. Wang, L. Zhang, Y. Xiu, and J. Jiao, "Electro-osmosis drainage experiment of unsaturated clayey soil", Engineering Mechanics, vol. 30, pp. 191-194, 2013. [http://dx.doi.org/10.3901/JME.2013.05.191]

[13] L. Zhang, N.W. Wang, L.P. Jing, C. Fang, Y.Q. Li, and Q. Cheng, "Experimental studies and engineering application of electro-osmotic consolidation of clay soil", Journal of Natural Disasters, vol. 25, pp. 78-86, 2016.

[14] L. Zhang, "Experimental and Theoretic Study on Electrochemical Stabilization of Soft Clay in Liaoning Province", M.S. Thesis, Shenyang Jianzhu University, Shenyang, China, 2014.

[15] J.Q. Shang, "Electroosmosis-enhanced preloading consolidation via vertical drains", Canadian Geotechnical Journal, vol. 35, pp. 491-499, 1998.

[http://dx.doi.org/10.1139/t98-018]

[16] Y.F. Zhuang, and Z. Wang, "Interface electric resistance of electroosmotic consolidation", J. Geotech. Geoenviron. Eng., vol. 133, pp. 1617-1621, 2007. [http://dx.doi.org/10.1061/(ASCE)1090-0241(2007)133:12(1617)]

[17] E.A. Ivliev, "Electro-osmotic drainage and stabilization of soils", Soil Mechanics and Foundation Engineering, vol. 45, pp. 211-218, 2008. [http://dx.doi.org/10.1007/s11204-009-9031-6]

[18] S.R. Kaniraj, and J.H. Yee, "Electro-osmotic consolidation experiments on an organic soil", Geotechnical and Geological Engineering, vol. 29, pp. 505-518, 2011.

[http://dx.doi.org/10.1007/s10706-011-9399-8]

[19] R.H. Liu, "A Study of Cemented Zones for Injection of Calcium Chloride Solution during Electroosmotic Chemical Treatment of Kaolinite", M.S. Thesis, National Taiwan University of Science and Technology, Taipei, Taiwan, 2011.

[20] Y.S. Lin, "Strength Improvement and Cementation Mechanism of Kaolinite in Electroosmotic Chemical Treatment", M.S. Thesis, National Taiwan University of Science and Technology, Taipei, Taiwan, 2014.

[21] C.A. Fetzer, "Electro-osmotic stabilization of west branch dam", Journal of Soil Mechanics \& Foundations Div, vol. 93, pp. 85-106, 1967.

[22] S.H. Chew, G.P. Karunaratne, V.M. Kuma, L.H. Lim, M.L. Toh, and A.M. Hee, "A field trial for soft clay consolidation using electric vertical drains", Geotextiles Geomembranes, vol. 22, pp. 17-35, 2004.

[http://dx.doi.org/10.1016/S0266-1144(03)00049-9]

[23] G. Lefebvre, and F. Burnotte, "Improvements of electroosmotic consolidation of soft clays by minimizing power loss at electrodes", Canadian Geotechnical Journal, vol. 39, pp. 399-408, 2002. [http://dx.doi.org/10.1139/t01-102]

[24] S.C. Chien, "A Study of Ground Improvement Using Electroosmotic Chemical Grouting", Ph.D Thesis, National Taiwan University of Science and Technology, Taipei, Taiwan, 2003.

[25] S.C. Chien, C.Y. Ou, and M.K. Wang, "Injection of saline solutions to improve the electro-osmotic pressure and consolidation of foundation soil", Applied Clay Science, vol. 44, pp. 218-224, 2009.

[http://dx.doi.org/10.1016/j.clay.2009.02.006]

[26] S.C. Chien, C.Y. Ou, and Y.H. Wang, "Soil improvement using electroosmosis with the injection of chemical solutions: laboratory tests", Journal of the Chinese Institute of Engineers, vol. 34, pp. 863-875, 2011. [http://dx.doi.org/10.1080/02533839.2011.591915] 
[27] D.H. Gray, "Electrochemical hardening of clay soils", Geotechnique, vol. 20, pp. 81-93, 1970. [http://dx.doi.org/10.1680/geot.1970.20.1.81]

[28] S. Ozkan, R.J. Gale, and R.K. Seals, "Electrokinetic stabilization of kaolinite by injection of Al and PO4-3 ions", Proceedings of ICE-Ground Improvement, vol. 3, pp. 135-144, 1999.

[http://dx.doi.org/10.1680/gi.1999.030401]

[29] P. Asavadorndeja, and U. Glawe, "Electrokinetic strengthening of soft clay using the anode depolarization method", Bulletin of Engineering Geology and the Environment, vol. 64, pp. 237-245, 2005. [http://dx.doi.org/10.1007/s10064-005-0276-7]

[30] C.Y. Ou, S.C. Chien, and Y.G. Wang, "On the enhancement of electroosmotic soil improvement by the injection of saline solutions", Applied Clay Science, vol. 44, pp. 130-136, 2009.

[http://dx.doi.org/10.1016/j.clay.2008.12.014]

[31] H.W. Chang, P.G. Krishna, S.C. Chien, C.Y. Ou, and M.K. Wang, "Electro-osmotic chemical treatments: effects of Ca2+ concentration on the mechanical strength and pH of kaolin", Clays and Clay Minerals, vol. 58, pp. 154-163, 2010. [http://dx.doi.org/10.1346/CCMN.2010.0580202]

[32] F.C. Teng, S.C. Chien, and C.Y. Ou, "Electro-osmotic chemical treatment of clay on shear modulus", Geotechnical Testing Journal, vol. 36, pp. 1-8, 2013. [http://dx.doi.org/10.1520/GTJ20120105]

[33] X.Q. Wang, and W.L. Zou, "Properties and applications of electro-kinetic geosynthetics", Journal of Wuhan University of Technology, vol. 24 , pp. 62-65, 2002.

[34] T.Y. Wan, and K.J. Mitchell, "Electro-osmotic consolidation of soils", J. Geotech. Eng. Div., vol. 102, pp. 473-491, 1976.

[35] G.R. Gao, Neoteric Soil Geotechnology, $2^{\text {nd }}$ ed. Science Press: Beijing, 2013.

[36] F. Yu, X. Wang, S. Chen, and C. Cheng, "Laboratory model test study of electrochemical stabilization in soft soil", Chinese Journal of Rock Mechanics and Engineering, vol. 32, pp. 2716-2722, 2013.

(C) Zhang et al.; Licensee Bentham Open

This is an open access article licensed under the terms of the Creative Commons Attribution-Non-Commercial 4.0 International Public License (CC BY-NC 4.0) (https://creativecommons.org/licenses/by-nc/4.0/legalcode), which permits unrestricted, non-commercial use, distribution and reproduction in any medium, provided the work is properly cited. 